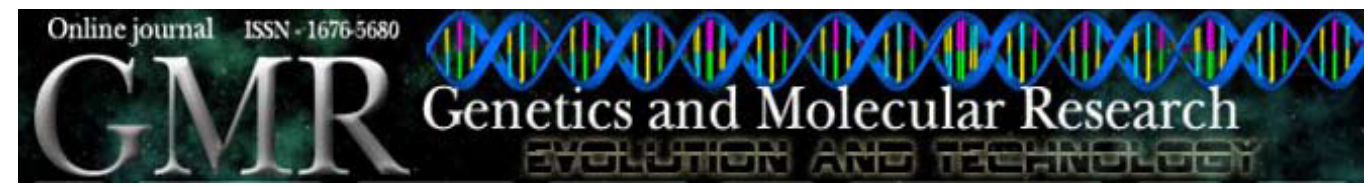

\title{
Correlation of polymorphism C3435T of the $M D R-1$ gene and the response of primary chemotherapy in women with locally advanced breast cancer
}

\author{
F.F.O. Rodrigues ${ }^{1}$, R.E. Santos ${ }^{1}$, M.B. Melo ${ }^{2}$, M.A.L.G. Silva ${ }^{3}$, \\ A.L. Oliveira ${ }^{1}$, R.L. Rozenowicz ${ }^{1}$, L.B. Ulson ${ }^{1}$ and T. Aoki ${ }^{1}$ \\ ${ }^{1}$ Departamento de Obstetrícia e Ginecologia, Santa Casa de São Paulo, \\ Faculdade de Ciências Médicas, São Paulo, SP, Brasil \\ ${ }^{2}$ Laboratório de Medicina Molecular, \\ Departamento de Ciências Fisiológicas, Santa Casa de São Paulo, \\ Faculdade de Ciências Médicas, São Paulo, SP, Brasil \\ ${ }^{3}$ Departamento de Patologia, Santa Casa de São Paulo, \\ Faculdade de Ciências Médicas, São Paulo, SP, Brasil \\ Corresponding author: F.F.O. Rodrigues \\ E-mail: foliveirarodrigues@uol.com.br
}

Genet. Mol. Res. 7 (1): 177-183 (2008)

Received November 15, 2007

Accepted December 27, 2007

Published February 19, 2008

\begin{abstract}
Primary chemotherapy is a useful strategy for the treatment of locally advanced breast cancer and therefore allows in vivo evaluation of the action of cytotoxic drugs and the possibility of accomplishing conservative breast surgeries, as well as the early treatment of metastasis. Mechanisms of resistance to the drugs include the action of protein associated with the efflux of drugs from the intracellular environment hindering their activity; one of the most studied proteins is P-glycoprotein codified by the $M D R-1$ gene. The presence of polymorphisms can determine different physiological actions of these proteins, intervening with the
\end{abstract}


response of the drug's action. We evaluated the presence of single nucleotide polymorphism (SNP) C3435T of the $M D R-1$ gene and its correlation with the response to primary chemotherapy using the RECIST criteria. Forty-one Brazilian women with stages II and III breast cancer using the PCR-RFLP analysis were evaluated. Thirtythree patients with the SNP genotype (TT and CT) and eight patients with the wild genotype (CC) were found; there was no statistically significant correlation between the diverse genotypes and the clinical and pathological responses according to the Cramer correlation coefficient $(\mathrm{V}=0.14)$. The parameters: nuclear and histological degree, and estrogens, progesterone and c-erb B2 receptors did not demonstrate a statistical correlation with the SNP C3435T. Patients with complete pathological response $(12.5 \%)$ showed only the polymorphic genotype and not the wild genotype. The characteristics of miscegenation in our population could explain the absence of the characterization of a sub-group of individuals where the presence of the polymorphic genotype influenced the response to the primary chemotherapy.

Key words: Polymorphism; P-glycoprotein; Chemotherapy; Breast cancer

\section{INTRODUCTION}

The treatment of breast cancer has undergone several changes, ever since the concept of radical surgery considered by Halsted, in 1894, up until the application of conservative surgeries by Fisher and Veronesi (Fisher et al., 1985; Veronesi et al., 1986). The use of chemotherapy prior to surgery was initially considered by de Lena et al. (1975) in patients with locally advanced breast cancer; later on, clinical and laboratory evaluation confirmed the systemic nature of breast cancer at the time of its diagnosis as demonstrated by Fisher and Bonadonna (Fisher et al., 1983; Bonadonna, 1989). From these concepts, several authors have widely used primary chemotherapy as a therapeutic modality for the treatment of locally advanced breast cancer (Hortobagyi et al., 1983; Bonadonna, 1989; Valagussa et al., 1990).

The use of the primary chemotherapy for patients with locally advanced breast cancer presents, in principle, the possibility of verifying the in vivo response to the therapy, the accomplishment of conservative breast surgeries when radical surgeries would be indicated and the early treatment of micrometastasis (Wolff and Davidson, 2000; Hutcheon and Heys, 2004). However, its use has not demonstrated benefits in the overall survival rate, in the disease-free survival rate and in the long-distance disease-free survival rate (Fisher et al., 1998).

One of the main reasons that can account for the failure of treatment in patients with cancer is the mechanism of drug resistance that can be determined by factors that affect the efflux and influx of drugs across the cell membrane (Terek et al., 2003; Leonessa and Clarke, 2003). Amongst these, the most studied is P-glycoprotein (Pgp), described by Juliano and Ling (1976), responsible for substance elimination by the cell membrane by hydrolysis of ATP and codified by the MDR-1 gene (Sauna et al., 2001). Some substrates related to the Pgp are widely 
used for breast cancer chemotherapy, such as anthracyclines and taxanes (Goldstein, 1996).

Roughly, 28 single nucleotide polymorphisms (SNP) related to the $M D R-1$ gene have been described and the most studied is the C3435T located in exon 26 (Brinkmann and Eichelbaum, 2001). Experimental studies have demonstrated that the basal expression of the MDR-1 gene is weak or absent when associated with TT genotype (Sauer et al., 2002). Hoffmeyer et al. (2000) and Kim et al. (2001) demonstrated that individuals with TT genotype showed low function of Pgp protein, when compared with CC individuals.

Kafka et al. (2003) demonstrated a significant correlation between the occurrence of TT genotype and the complete clinical response in patients with locally advanced breast cancer submitted to primary chemotherapy with anthracycline.

The goal of the present study was to demonstrate the correlation between SNP C3435T of the $M D R-1$ gene and the clinical and pathological responses in Brazilian patients with stages II and III breast cancer who were submitted to primary chemotherapy.

\section{MATERIAL AND METHODS}

This was a longitudinal and prospective study, where 41 patients were selected between July 2004 and July 2006 and submitted to biopsy of the breast for diagnostic confirmation of invasive ductal carcinoma, with only unilateral tumors, in stages II and III according to criteria proposed by the UICC, 6th edition. All patients had been submitted to three cycles of neoadjuvant chemotherapy, with 21-day intervals, according to the regimen: 5-fluorouracil $\left(500 \mathrm{mg} / \mathrm{m}^{2}\right)$, epirubicin $\left(75 \mathrm{mg} / \mathrm{m}^{2}\right)$ and cyclophosphamide (500 $\mathrm{mg} / \mathrm{m}^{2}$ ) on day one. For each cycle, the patients were evaluated according to RECIST's criteria (Therasse et al., 2000).

In the present study, responsive patients (RP) were considered to be those who showed complete or partial response; nonresponsive patients (NRP), those with steady illness and progression. The complete pathological response was considered as absence of invasive neoplasia or in situ neoplasia (Sataloff et al., 1995). This study was approved by the Research Ethics Committee of the Santa Casa Hospital of São Paulo.

\section{Extraction of DNA and polymerase chain reaction}

Peripheral blood samples were collected from the patients in sterile tubes containing EDTA, where the genomic DNA was extracted and later amplified by polymerase chain reaction (PCR) to obtain the fraction of $249 \mathrm{bp}$ that included the polymorphic region C3435T located in exon 26, using the primers sense 5'-ATG GGC TCC GAG CAC ACC TG-3' and antisense 5'-AGG CAG TGA CTC GAT GAA GGC-3' (Invitrogen ${ }^{\text {TM }}$ Life Technologies, Carlsbad, CA, USA). We used an Eppendorf PCR thermocycler (Eppendorf GAC 22331, Hamburg, Germany) with the following standardization: initial denaturation at $94^{\circ} \mathrm{C}$ for 5 min followed by 35 cycles of denaturation at $94^{\circ} \mathrm{C}$ for $1 \mathrm{~min}$, annealing at $53^{\circ} \mathrm{C}$ for $1 \mathrm{~min}$, and extension at $72^{\circ} \mathrm{C}$ for $1.5 \mathrm{~min}$, with a final extension at $72^{\circ} \mathrm{C}$ for $7 \mathrm{~min}$.

\section{Digestion with restriction enzyme}

The identification of SNP C3435T of the MDR-1 gene was determined by diges- 
tion with the restriction enzyme Sau3AI (New England BioLabs, USA), using $1 \mu \mathrm{L}$ of enzyme and $3 \mu \mathrm{L}$ of the PCR product in proper drain plug and incubating the reaction mixture at $37^{\circ} \mathrm{C}$ for $3 \mathrm{~h}$. The genotype was identified by electrophoresis on a $2.5 \%$ agarose gel and comparing it with a 50-bp marker stained with ethidium bromide and visualized under ultraviolet light.

The enzyme Sau3AI promoted the cleavage of DNA producing specific bands observed on the gel, where CC genotype was disclosed as two fragments of DNA of 158 and 91 $\mathrm{bp}$, the TT demonstrated only one fragment of $249 \mathrm{bp}$ and the CT displayed three fragments of 91,158 and $249 \mathrm{bp}$.

The photographic documentation was performed using a digital camera, Canon model Rebel XT (Digital Canon EOS Rebel XT, EF-S 18-55, Japan).

\section{Statistical analysis}

For statistical analysis the Microsoft Excel ${ }^{\circledR}$, version 2003, software was used to build our database and the Statistical Software Package SPSS ${ }^{\circledR}$, version 2003 (SPSS Incorporation, Chicago, IL, USA), software was used for elaboration of the statistical tests used for the Cramer correlation, non-parametric test and function statistics of the chi-square test. A P value of $<0.05$ was considered statistically significant.

\section{RESULTS}

The measure of the tumors prior to the chemotherapy varied from 2.5 to $15 \mathrm{~cm}$ with an average of $5.79 \mathrm{~cm}$; after 3 cycles of chemotherapy, the largest diameter of the tumors varied from 0 to $8.5 \mathrm{~cm}$ with an average of $3.59 \mathrm{~cm}$. The clinical response showed the following distribution: 25 patients were classified as RP and 16 as NRP. The distribution of the genotypes disclosed 16 patients with CT genotype, 17 with TT and 8 with CC.

The incidence based on race demonstrated, for white individuals, 10 patients with CT genotype, 11 patients with TT and six with CC; and for black individuals, 6 patients with CT, 6 with TT and 2 with CC.

The correlation between RP and NRP who carried the polymorphic alleles (CT and TT) or wild allele (CC) was not statistically significant, as shown in Table 1. The comparison between the neoplastic axillary involvement and the diverse alleles did not demonstrate a statistically significant correlation, as shown in Table 2 .

The histological and nuclear grades did not show a significant correlation with the CT/ TT and CC genotypes (with $\mathrm{V}=0.1216$ and 0.0461 , respectively).

Table 1. Correlation between the frequencies of CT/TT and wild (CC) allele polymorphisms and responsive (RP)
and nonresponsive patients (NRP), submitted to primary chemotherapy.
\begin{tabular}{lrrr}
\hline Allele polymorphism & RP & NRP & Total \\
\hline CT + TT & 19 & 14 & 33 \\
CC & 6 & 2 & 8 \\
Total & 25 & 16 & 41 \\
\hline
\end{tabular}

Cramer's correlation coefficient; $\mathrm{V}=0.1415$. 


\begin{tabular}{lcccc}
\multicolumn{4}{l}{ Table 2. Correlation between the frequencies of SNP C3435T and neoplastic axillary involvement (LN). } \\
\hline SNP & 0 LN & 1 to 4 LN & $\geq 5$ LN & Total \\
\hline CT & 8 & 3 & 5 & 16 \\
TT & 8 & 2 & 7 & 17 \\
CC & 5 & 2 & 1 & 8 \\
Total & 21 & 7 & 13 & 41 \\
\hline
\end{tabular}

Cramer's correlation coefficient; $\mathrm{V}=0.2077$.

The distribution of the patients according to expression of the estrogen, progesterone and c-erb B2 receptors did not demonstrate a significant correlation with the CT/TT and CC genotypes (with $\mathrm{V}=0.1107,0.0853$ and 0.0853 , respectively).

Complete pathological response was verified in 5 patients, with 3 patients having the CT genotype and 2 the TT genotype; no patient had the CC genotype.

\section{DISCUSSION}

Despite the diverse chemotherapy regimens used for the treatment of breast cancer, the rates of complete clinical response range between 17 and 80\% (Bonadonna et al., 1990; Fisher et al., 1997) and the complete pathological response is considered to be between 5.9 and 13\% (Bonadonna et al., 1990; Semiglazov et al., 1994). In the present study, 25 (60.98\%) patients were classified as RP and 5 (12.9\%) showed complete pathological response.

The search for new prognostic and predictive markers is important for the development of even more specific and individualized treatments, optimizing results and reducing the collateral effects (Kafka et al., 2003; Ayers et al., 2004; Tripathy, 2005).

In this context, we decided to analyze the significance of SNP C3435T of the $M D R-1$ gene and its correlation with the clinical and pathological responses in Brazilian patients with breast cancer submitted to primary chemotherapy, through the RFLP technique whose use has been widely reported in the literature due to its simplicity (Cavaco et al., 2003; Balram et al., 2003).

In the present study, the general distribution of the genotypes was $19.5 \%$ for CC individuals, $39.04 \%$ for $\mathrm{CT}$ and $41.46 \%$ for TT; other authors (Rodrigues et al., 2005) have found distribution patterns with $27.9 \%$ for CC, $52.2 \%$ for CT and $20.3 \%$ for TT. The distribution according to race demonstrated that $51.21 \%$ of the SNP individuals were of the white race and $29.26 \%$ were of the black race; other authors have demonstrated that the incidence of the SNP was detected in $43.3 \%$ of Euro-American individuals and $69.5 \%$ of Afro-Americans (Kim et al., 2001).

The incidence of SNP C3435T of the MDR-1 gene did not correlate, in this study, with cancer staging, the presence of axillary metastasis and histological and nuclear grades, similar to the findings of various authors (de La Torre et al., 1994; Chevillard et al., 1996; Kafka et al., 2003).

The expression of estrogen, progesterone and c-erb B2 receptors was not correlated with SNP C3435T of the MDR-1 gene, as has been demonstrated by other authors (Dexter et al., 1998; Kafka et al., 2003).

The clinical response did not show a significant correlation with SNP C3435T, similar 
to the findings of Kafka et al. (2003). The pathological response did not show a significant correlation in our study, findings conflicting with the literature that demonstrates a frequent association between TT genotype and complete pathological response (Kafka et al., 2003), although it allowed us to verify that such finding was attributed to the polymorphic genotypes (CT/TT) and not to the wild genotype (CC). The association found by Kafka et al. (2003) makes sense when we take into consideration previous studies that have described the diverse functional character of the alleles associated with SNP C3435T, where TT genotype was correlated with reduced expression and functional status of Pgp protein and, therefore, reduced cellular elimination and blood concentration of chemotherapeutic drug (Hoffmeyer et al., 2000; Kim et al., 2001).

Thus, the expression of the polymorphic genotype would cause greater bioavailability of the drug and optimization of its cytotoxic effect.

The miscegenation of our sample, which showed a peculiar distribution, could explain the fact of not characterizing a sub-group of polymorphic individuals where we could demonstrate a statistically significant association with the clinical and pathological responses to primary chemotherapy. More population studies must be carried out in order to determine the true role of SNP C3435T in the treatment of breast cancer.

\section{ACKNOWLEDGMENTS}

Research supported by an FAP/FCMSC grant. We are grateful to the Support Center for Scientific Publications of Santa Casa de São Paulo, Faculty of Medical Sciences, for the editorial assistance.

\section{REFERENCES}

Ayers M, Symmans WF, Stec J, Damokosh AI, et al. (2004). Gene expression profiles predict complete pathologic response to neoadjuvant paclitaxel and fluorouracil, doxorubicin, and cyclophosphamide chemotherapy in breast cancer. J. Clin. Oncol. 22: 2284-2293.

Balram C, Sharma A, Sivathasan C and Lee EJ (2003). Frequency of C3435T single nucleotide MDR1 genetic polymorphism in an Asian population: phenotypic-genotypic correlates. Br. J. Clin. Pharmacol. 56: 78-83.

Bonadonna G (1989). Karnofsky memorial lecture. Conceptual and practical advances in the management of breast cancer. J. Clin. Oncol. 7: 1380-1397.

Bonadonna G, Veronesi U, Brambilla C, Ferrari L, et al. (1990). Primary chemotherapy to avoid mastectomy in tumors with diameters of three centimeters or more. J. Natl. Cancer Inst. 82: 1539-1545.

Brinkmann U and Eichelbaum M (2001). Polymorphisms in the ABC drug transporter gene MDR1. Pharmacogenomics J. 1: 59-64.

Cavaco I, Gil JP, Gil-Berglund E and Ribeiro V (2003). CYP3A4 and MDR1 alleles in a Portuguese population. Clin. Chem. Lab. Med. 41: 1345-1350.

Chevillard S, Pouillart P, Beldjord C, Asselain B, et al. (1996). Sequential assessment of multidrug resistance phenotype and measurement of S-phase fraction as predictive markers of breast cancer response to neoadjuvant chemotherapy. Cancer 77: 292-300.

de la Torre M, Larsson R, Nygren P, Lindgren A, et al. (1994). Expression of the multidrug-resistance gene product in untreated human breast cancer and its relationship to prognostic markers. Acta Oncol. 33: 773-777.

de Lena M, Brambilla C, Morabito A and Bonadonna G (1975). Adriamycin plus vincristine compared to and combined with cyclophosphamide, methotrexate, and 5-fluorouracil for advanced breast cancer. Cancer 35: 1108-1115.

Dexter DW, Reddy RK, Geles KG, Bansal S, et al. (1998). Quantitative reverse transcriptase-polymerase chain reaction measured expression of MDR1 and MRP in primary breast carcinoma. Clin. Cancer Res. 4: 1533-1542.

Fisher B, Bauer M, Wickerham DL, Redmond CK, et al. (1983). Relation of number of positive axillary nodes to the 
prognosis of patients with primary breast cancer. An NSABP update. Cancer 52: 1551-1557.

Fisher B, Bauer M, Margolese R, Poisson R, et al. (1985). Five-year results of a randomized clinical trial comparing total mastectomy and segmental mastectomy with or without radiation in the treatment of breast cancer. N. Engl. J. Med. 312: 665-673.

Fisher B, Brown A, Mamounas E, Wieand S, et al. (1997). Effect of preoperative chemotherapy on local-regional disease in women with operable breast cancer: findings from National Surgical Adjuvant Breast and Bowel Project B-18. $J$. Clin. Oncol. 15: 2483-2493.

Fisher B, Bryant J, Wolmark N, Mamounas E, et al. (1998). Effect of preoperative chemotherapy on the outcome of women with operable breast cancer. J. Clin. Oncol. 16: 2672-2685.

Goldstein LJ (1996). MDR1 gene expression in solid tumours. Eur. J. Cancer 32A: 1039-1050.

Halsted WS (1894). The results of operation for the cure of cancer of the breast performed at the Johns Hopkins Hospital from June 1889 to January 1894. Ann. Surg. [periodical on line] 20: 497-555. http://www.pubmedcentral.nih.gov/ articlerender.fcgi?artid=1493925. Accessed August 16, 2006.

Hoffmeyer S, Burk O, von Richer O, Arnold HP, et al. (2000). Functional polymorphisms of the human multidrugresistance gene: multiple sequence variations and correlation of one allele with P-glycoprotein expression and activity in vivo. Proc. Natl. Acad. Sci U. S. A. 97: 3473-3478.

Hortobagyi GN, Blumenschein GR, Spanos W, Montague ED, et al. (1983). Multimodal treatment of locoregionally advanced breast cancer. Cancer 51: 763-768.

Hutcheon AW and Heys SD (2004). Primary systemic chemotherapy of large and locally advanced breast cancer. ASCO, 1092-9118: 63-79.

Juliano RL and Ling V (1976). A surface glycoprotein modulating drug permeability in Chinese hamster ovary cell mutants. Biochim. Biophys. Acta 455: 152-162.

Kafka A, Sauer G, Jaeger C, Grundmann R, et al. (2003). Polymorphism C3435T of the MDR-1 gene predicts response to preoperative chemotherapy in locally advanced breast cancer. Int. J. Oncol. 22: 1117-1121.

Kim RB, Leake BF, Choo EF, Dresser GK, et al. (2001). Identification of functionally variant MDR1 alleles among European Americans and African Americans. Clin. Pharmacol. Ther. 70: 189-199.

Leonessa F and Clarke R (2003). ATP binding cassette transporters and drug resistance in breast cancer. Endocr. Relat. Cancer 10: 43-73.

Rodrigues AC, Rebecchi IM, Bertolami MC, Faludi AA, et al. (2005). High baseline serum total and LDL cholesterol levels are associated with MDR-1 haplotypes in Brazilian hypercholesterolemic individuals of European descent. Braz. J. Med. Biol. Res. 38: 1389-1397.

Sataloff DM, Mason BA, Prestipino AJ, Seinige UL, et al. (1995). Pathologic response to induction chemotherapy in locally advanced carcinoma of the breast: a determinant of outcome. J. Am. Coll. Surg. 180: 297-306.

Sauer G, Kafka A, Grundmann R, Kreienberg R, et al. (2002). Basal expression of the multidrug resistance gene 1 (MDR-1) is associated with the TT genotype at the polymorphic site C3435T in mammary and ovarian carcinoma cell lines. Cancer Lett. 185: 79-85.

Sauna ZE, Smith MM, Müller M, Kerr KM, et al. (2001). The mechanism of action of multidrug-resistance-linked P-glycoprotein. J. Bioenerg. Biomembr. 33: 481-491.

Semiglazov VF, Topuzov EE, Bavli JL, Moiseyenko VM, et al. (1994). Primary (neoadjuvant) chemotherapy and radiotherapy compared with primary radiotherapy alone in stage IIb-IIIa breast cancer. Ann. Oncol. 5: 591-595.

Terek MC, Zekioglu O, Sendag F, Akercan F, et al. (2003). MDR1 gene expression in endometrial carcinoma. Int. J. Gynecol. Cancer 13: 673-677.

Therasse P, Arbuck SG, Eisenhauer EA, Wanders J, et al. (2000). New guidelines to evaluate the response to treatment in solid tumors. European Organization for Research and Treatment of Cancer, National Cancer Institute of the United States, National Cancer Institute of Canada. J. Natl. Cancer Inst. 92: 205-216.

Tripathy D (2005). Targeted therapies in breast cancer. Breast J. 11 (Suppl 1): S30-S35.

Valagussa P, Zambetti M, Bonadonna G, Zucali R, et al. (1990). Prognostic factors in locally advanced noninflammatory breast cancer. Long-term results following primary chemotherapy. Breast Cancer Res. Treat. 15: 137-147.

Veronesi U, Banfi A, Del Vecchio M, Saccozzi R, et al. (1986). Comparison of Halsted mastectomy with quadrantectomy, axillary dissection, and radiotherapy in early breast cancer: long-term results. Eur. J. Cancer Clin. Oncol. 22: 10851089.

Wolff AC and Davidson NE (2000). Primary systemic therapy in operable breast cancer. J. Clin. Oncol. 18: 1558-1569. 